\title{
Incidental prostate cancer: a 10-year review of a tertiary center,Tehran, Iran
}

This article was published in the following Dove Press journal: Research and Reports in Urology

\author{
Amir-reza Abedi' \\ Morteza Fallah-Karkan² \\ Farzad Allameh' \\ Arash Ranjbar' \\ Afshin Shadmehr ${ }^{3}$ \\ 'Urology Department, Shohada-e- \\ Tajrish Hospital, Shahid Beheshti \\ University of Medical Sciences, Tehran, \\ Iran; ${ }^{2}$ Urology Department, Shohada- \\ e-Tajrish Hospital, Laser Application \\ in Medical Sciences Research Center, \\ Shahid Beheshti University of Medical \\ Sciences, Tehran, Iran; ${ }^{3}$ Urology \\ Department, Isfahan University of \\ Medical Sciences, Isfahan, Iran
}

Objective: Incidental prostate cancer (IPCa) is defined as a symptom-free cancer unexpectedly discovered upon microscopic examination of resected tissue. The aim of this study was to report the correlation between some specific clinical criteria in patients incidentally diagnosed with prostate cancer (PCa) during transurethral resection of the prostate (TURP) or open prostatectomy (OP) after clinically suspected benign prostatic hyperplasia.

Patients and methods: This was a cross-sectional, retrospective study. Data were collected from Shohada-e-Tajrish Hospital database during November 2006 to October 2016. Four hundred and twenty three men suffering from symptomatic benign prostatic hyperplasia who underwent either TURP or OP that provided a prostate specimen were evaluated. The data analysis was performed using Pearson correlation test and independent $t$-test using SPSS version 20 software. Results: The mean age of subjects was $68.74 \pm 9.87$ years old ( $45-93$ years). The mean prostate specific antigen (PSA) level was $21.47 \pm 13.44 \mathrm{ng} / \mathrm{mL}(0.6-47.1 \mathrm{ng} / \mathrm{mL})$. Results showed that 84 patients (19.9\%) had PCa (40 patients who underwent TURP [12.6\%] and 44 patients who underwent OP [40.7\%] groups). Cut-off point of PSA for detecting IPCa was $3.8 \mathrm{ng} / \mathrm{mL}$ in our study, and this showed sensitivity, specificity, negative predictive value, and positive predictive value of $26.08 \%, 100 \%, 100 \%$, and $29.79 \%$, respectively. Twenty two patients with cancer had a positive family history for $\mathrm{PCa}$; thus, a significant relationship between familial history of $\mathrm{PCa}$ and its occurrence was shown $(p=0.0001)$.

Conclusion: According to the results of this study, the cut-off point for PSA levels in detecting PCa was $3.8 \mathrm{ng} / \mathrm{mL}$, which is similar to that reported by other studies. Familial history of PCa and PSA levels were two predictors in determining the PCa.

Keywords: incidental prostate cancer, transurethral resection of the prostate, open prostatectomy, prostate cancer, Iran

\section{Introduction}

Prostate cancer (PCa) is the most frequent malignancy in males older than $65,{ }^{1}$ with an estimated 41,000 Americans dying from PCa annually. ${ }^{2}$ Epidemiologic reports showed alterations in the geographic and racial prevalence of PCa. It has a low incidence in Asia (3-8 per 100,000 men/yr), an intermediate incidence in Africa and Eastern Europe, and higher incidence in Western Europe and North America. ${ }^{3}$ Mostly, cancers arise in the prostate with concomitant benign prostatic hyperplasia (BPH, 83.3\%), and they are most often found accidentally in a great number of transuretheral resection of the prostate (TURP) samples. The clinical incidence of cancer arising in patients with surgically treated $\mathrm{BPH}$ is approximately $3 \% .{ }^{4}$ Cases may also be underdiagnosed. In autopsy reports, the prevalence of histologically confirmed PCa was up to $29 \%$ in men between
Correspondence: Morteza Fallah-Karkan Urology Department, Shohada-e-Tajrish Hospital, Laser Application in Medical Sciences Research Center, Shahid Beheshti University of Medical Sciences, Tehran 43I58-48737, Iran

Tel +982122736386

Email mortezafallah.md@gmail.com 
30 and 40 years, and 64\% in men aged $60-70$ years. ${ }^{5} \mathrm{PCa}$ is a main reason for mortality among men in developed countries. ${ }^{6}$ There are many recommendations for carrying out PCa screening by using the prostate specific antigen (PSA) test, in many countries, ${ }^{7}$ despite the recommendation, the harms caused by overdiagnosis and overtreatment must be considered. ${ }^{8}$

Incidental PCa (IPCa) is defined as a "cancer which lacks apparent neoplastic symptoms or cancer which is unusually detected by microscopic examination of resected tissue that had been previously diagnosed as benign." ${ }^{\circ}$ Today, PCa is more frequently being diagnosed in asymptomatic patients with localized disease. Owing to early diagnosis, more cases of focal PCa or IPCa are diagnosed..$^{9,10}$ There is also a population group composed of patients with obstructive lower urinary tract symptoms (LUTS) that are probably an outcome of BPH. These patients do not manifest with clinical symptoms nor does the disease show up on digital rectal examination (DRE), and they often have normal PSA levels. On the contrary, it is possible that some patients undergo one or more transrectal biopsies because of alterations observed on DRE or in PSA levels, but with pathological biopsy examinations not revealing any neoplastic changes. ${ }^{11}$

The aim of our study was to report our experience in patients with specific clinical criteria who were incidentally diagnosed with prostate cancer during TURP or open prostatectomy (OP) for clinically suspected BPH.

\section{Materials and methods}

This was a cross-sectional, retrospective study. Data were collected from Shohada-e-Tajrish Hospital, Shahid Beheshti Medical University, Tehran, Iran, during November 2006 to October 2016. The case notes of patients who presented with symptomatic prostate enlargement and underwent either TURP or OP were evaluated. Four hundred and thirty seven men, aged from 45 to 93 years, were identified, who underwent a TURP or OP of the prostate.

\section{Inclusion criteria}

Histopathological confirmation of BPH in patients who had undergone transrectal ultrasound-guided biopsy (TRUS$\mathrm{Bx}$ ) prior to surgery and documentation of PSA level and a postoperation histopathology report was a requirement for inclusion in this study.

\section{Exclusion criteria}

The exclusion criteria were as follows: TURP patients previously diagnosed with $\mathrm{PCa}$ and histopathological studies of surgeries performed at another institution.

\section{Data collection}

A database was created that included such details as age, positive PCa family history in first-degree relatives, prostate volume, PSA level, previous biopsies, and histopathological results.

\section{Ethics}

This study was approved by the ethical committee of Shohada-e-Tajrish Hospital. Owing to the retrospective nature of the study, the ethical committee of Shohada-e-Tajrish Hospital waived the necessity to have patients provide consent to review their medical records. The authors used the patients' data for research purposes only. The patient health data were accessed confidentially and de-identified.

\section{Statistics}

Data analysis was done using Statistical Package for the Social Sciences version 20 software (IBM Corporation, Armonk, NY, USA). Mean \pm standard deviation, frequency, and percentage were used for reporting descriptive variables. The Pearson correlation test was used to test for association between qualitative variables. Independent $t$-test was used for quantitative variables. $P$-value $<0.05$ was considered as significant.

\section{Results}

\section{Demographic data}

Four hundred and twenty three patients with a mean age of $68.74 \pm 9.87$ years (45-93 years) were included in this study. Most of the patients were aged between 60 and 69 years (41.4\%), and the majority of them underwent TURP (74.5\%). Demographic data are summarized in Table 1.

\section{Prostate indexes}

The mean PSA level was $21.47 \pm 13.44 \mathrm{ng} / \mathrm{mL}(0.6-47.1$ $\mathrm{ng} / \mathrm{mL}$ ), and most patients had a PSA level greater than

Table I Demographic data of subjects

\begin{tabular}{lll}
\hline Characteristics & Years & $\mathbf{n}(\%)$ \\
\hline Age group & $40-49$ & $25(5.9)$ \\
& $50-59$ & $40(9.5)$ \\
& $60-69$ & $175(41.4)$ \\
& $70-79$ & $114(27)$ \\
& $80-89$ & $63(14.9)$ \\
Age (mean $\pm \mathrm{SD})$ & $90-99$ & $6(1.4)$ \\
Type of surgery (N, \%) & $68.74 \pm 9.87$ & \\
TURP & & \\
OP & & $315(74.5)$ \\
\hline Abbreviations: & & $108(25.5)$ \\
\hline
\end{tabular}

Abbreviations: OP, open prostastectomy; SD, standard deviation; TURP, transuretheral resection of the prostate. 
$4 \mathrm{ng} / \mathrm{mL}$ (72.6\%). The mean prostate volume was $80.56 \pm 25.12$ $\mathrm{mL}(40-142 \mathrm{~mL})$. The distribution of clinical data in the two groups is provided in Table 2 .

There was a significant relationship between age groups and PSA level ( $p=0.0001)$, a positive correlation between age and prostate volume $(r=0.812, p=0.0001)$, and also a significant correlation between PSA and age $(r=0.341$, $p=0.0001)$. PSA level was significantly different between the two groups $(p<0.0001)$ (Figure 1$)$. We showed that PSA $(p=0.0001)$ and positive familial history $(p=0.0001)$ were significant predictors of IPCa.

\section{Prostate cancer}

The results of the present study illustrate that $19.9 \%$ of patients had PCa. There was a significant relationship between PSA level (cut-off point: $4 \mathrm{ng} / \mathrm{mL})(p=0.0001)$ and prostate volume $(p=0.0001)$ with occurrence of $\mathrm{PCa}$. Twenty two patients with cancer had a positive $\mathrm{PCa}$ family history (14 in brothers and eight in fathers), and so the significant relationship between familial history of $\mathrm{PCa}$ and its

Table 2 Distribution of clinical data of patients in the two groups (OP and TURP)

\begin{tabular}{llll}
\hline Characteristics & TURP & OP & p-value \\
\hline PSA (n [\%]) & & & \\
$\quad \leq 4 \mathrm{ng} / \mathrm{mL}$ & $110(34.9)$ & $6(5.6)$ & $0.000 I^{*}$ \\
$\quad>4 \mathrm{ng} / \mathrm{mL}$ & $205(65.1)$ & $102(94.4)$ & \\
$\begin{array}{l}\text { Prostate volume } \\
\text { (mean } \pm \text { SD), } \mathrm{mL}\end{array}$ & $67.96 \pm 12.1$ & $117.3 \pm 15.15$ & $0.00 I^{* *}$ \\
\hline
\end{tabular}

Notes: $* \chi^{2}$ test, $* *$ Mann-Whitney test.

Abbreviations: OP, open prostastectomy; PSA, prostate specific antigen; SD, standard deviation; TURP, transuretheral resection of the prostate.

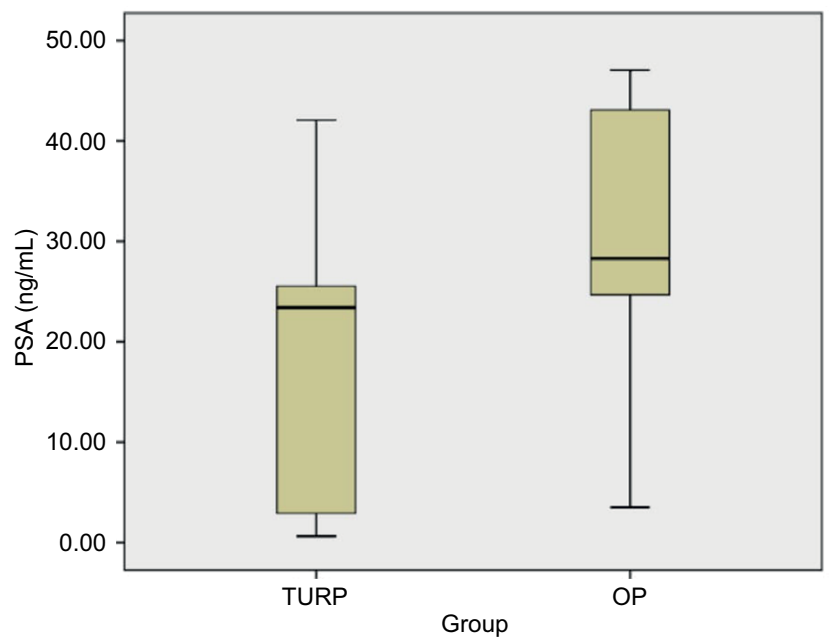

Figure I Mean PSA level between the two groups (TURP and OP).

Abbreviation: OP, open prostastectomy; PSA, prostate specific antigen; TURP, transuretheral resection of the prostate. occurrence ( $p=0.0001)$ was proven. There was a significant relationship between history of needle biopsy $(p=0.005)$ and palpable nodule on examination $(p=0.042)$ with occurrence of PCa $(p=0.001)$. PCa was detected in 40 patients who underwent TURP (12.6\%) and in 44 patients who underwent OP (40.7\%). There was a significant difference in the occurrence of IPCa in both groups. Cut-off point for PSA level to detect IPCa was set at $3.8 \mathrm{ng} / \mathrm{mL}$ in this study, and this showed sensitivity, specificity, negative predictive value, and positive predictive value of $26.08 \%, 100 \%, 100 \%$, and $29.79 \%$, respectively (Figure 2). The most common Gleason score was 6 in $43(71.1 \%$ ) patients followed by 7 (type 3+4) in 26, 7 (type $4+3$ ) in 11 , and 8 in four subjects, respectively. About $3.5 \%$ of patients had positive history of TRUS-Bx $(1.6 \%$ in TURP group and $9.3 \%$ in OP group). Seventy eight percent of patients with prior needle biopsy, had had PCa $(p=0.002)$, and $83 \%$ of patients with nodule on DRE had PCa $(p=0.037)$.

Of 40 subjects in the TURP surgery group, investigation of 30 patient records after intervention showed that 21 were managed by radical prostatectomy, five patients were treated with hormones plus radiotherapy, three of them were on active

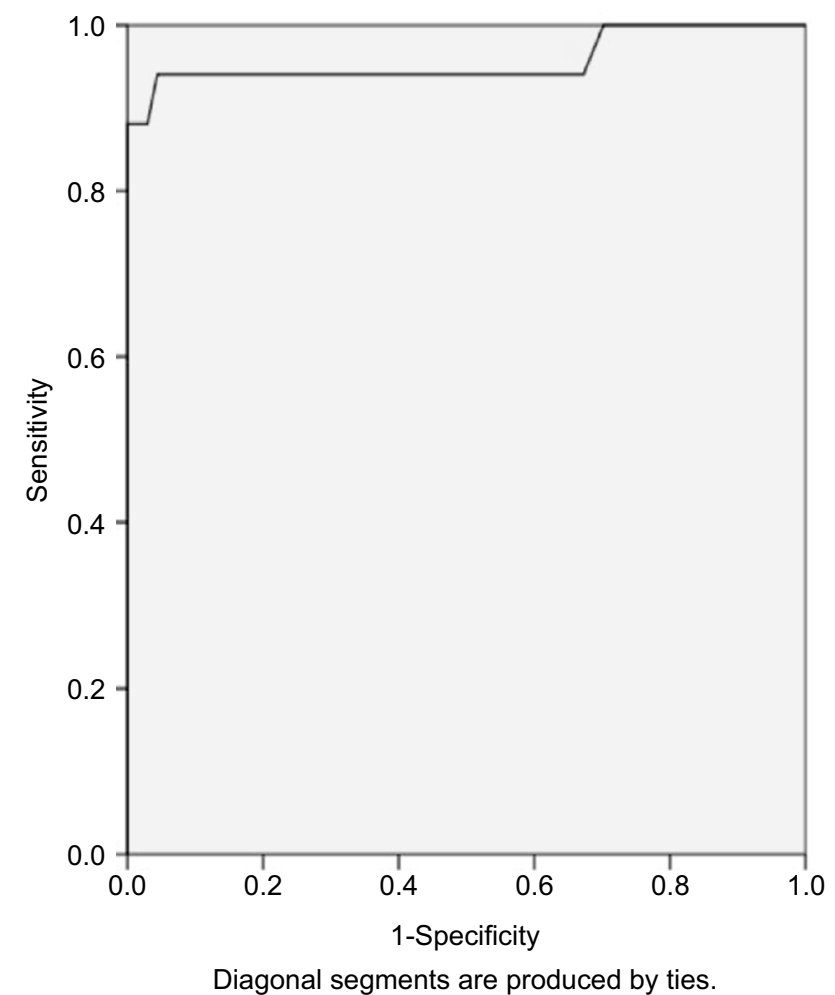

Figure 2 Sensitivity and specificity of PSA for detection of IPCa. Note: AUC was 0.95 .

Abbreviations: AUC, area under the curve; IPCa, incidental prostate cancer; PSA, prostate specific antigen; ROC, receiver operating characteristic. 
surveillance, and one patient was in the category of watchful waiting. Of 44 subjects in the OP surgery group, investigation of 33 patient records showed that just 11 patients were being treated with radical prostatectomy, 10 patients were treated with hormones plus radiotherapy, eight were on active surveillance, and four patients were in the category of watchful waiting.

\section{Discussion}

Our study showed an IPCa rate of $19.9 \%$. This detection rate is in line with that reported by several other recently published series. ${ }^{1,4,12-14}$ Also, our results demonstrated that PSA levels were significantly higher in the OP group than the TURP group. We showed that despite the fact that PSA is a highly sensitive test for detection of IPCa, it is not specific and may have a higher rate of false-positives. In our study, PSA level was significantly different between the two groups $(p<0.0001)$. There was a significant relationship between PSA level (cut-off point: $4 \mathrm{ng} / \mathrm{mL})(p=0.0001)$ and prostate volume ( $p=0.0001$ ) with the occurrence of PCa.

We demonstrated $\mathrm{PCa}$ in 40 patients who underwent TURP (12.6\%) and 44 patients who underwent OP (40.7\%), with significant difference between the occurrences of IPCa between both groups. However, because of the retrospective nature of our analysis, the distribution of patients in the two groups was not equivalent. Before using PSA for screening of PCa, the prevalence of this cancer was more than $27 \%$ in TURP. ${ }^{15}$ Detection rate of $\mathrm{PCa}$ ranged from $4.8 \%$ to $16.7 \%$ in previous investigations. ${ }^{12,16-19}$ Sometimes, following incidental detection of prostate cancer after TURP, patients might undergo more diagnostic procedures and other assessments to detect the cancer. In a study by Lee et $\mathrm{al}^{20} 63$ patients underwent TRUS-Bx or radical prostatectomy procedures after being diagnosed with IPCa. In 22 patients who underwent TRUS-Bx, $54 \%$ were downgraded to benign. Lee et $\mathrm{al}^{21}$ reported that in most cases TRUS-Bx did not provide enough additional information to warrant pursuing treatment for TURP-diagnosed IPCa. Voigt et $\mathrm{al}^{16}$ showed an IPCa rate of $11.1 \%$ in their study. They stated that age, volume of the prostate, and body mass index were predictive factors for IPCa. In Helfand et al's study, ${ }^{18}$ by searching for postoperative variations in PSA and PSA velocity in patients undergoing surgical management of BPH, they showed an IPCa rate of $8.7 \%$ in 313 patients who underwent TURP. They showed that patients with IPCa had a meaningful higher postoperative mean PSA velocity in comparison to patients without PCa (0.38 vs $0.06 \mathrm{ng} / \mathrm{mL} / \mathrm{yr}$ TURP and $0.47 \mathrm{vs}-0.13 \mathrm{ng} / \mathrm{mL} / \mathrm{yr}$ OP; $p<0.05)$. Trpkov et $\mathrm{al}^{22}$ have reported the highest IPCa rate in the PSA era, 16.7\%; but, they enrolled patients with known $\mathrm{PCa}$. A recent multicenter review by Yoo et $\mathrm{al}^{19}$ showed an IPCa rate of $4.8 \%$ in over 1,600 patients. They demonstrated that the combination of transitional zone volume and PSA can be helpful predictors of IPCa in addition to DRE findings. Otto et $\mathrm{al}^{23}$ reported a detection rate of $1.4 \%$ for their retrospective study of IPCa. According to these abovementioned studies and our study, it can be concluded that overall prevalence of IPCa is decreased.

Our results showed that there was a meaningful relation between PSA level (cut-off point: $4 \mathrm{ng} / \mathrm{mL}$ ) and prostate volume with occurrence of $\mathrm{PCa}$, and the cut-off point of PSA for detecting IPCa was $3.8 \mathrm{ng} / \mathrm{mL}$ in our study, which showed sensitivity, specificity, negative predictive value, and positive predictive value $26.08 \%, 100 \%, 100 \%$, and $29.79 \%$ respectively. In fact, PSA screening can increase the detection of PCa by increasing the use of prostate biopsy. Therefore, the majority of prostate cancers can be distinguished in primary stages and at a younger age, before they present with lower urinary tract syndrome. Before PSA was used as a diagnostic aid, the probability of IPCa transforming to locally advanced PCa was higher, due to lack of PSA screening. Additionally, using PSA levels for prostate biopsy strategy, concomitant TURP and prostate biopsy are being performed in patients with PSA levels more than $4.0 \mathrm{ng} / \mathrm{mL}$. Diagnosis of IPCa cannot be made if concomitant TURP and prostate biopsy are done together, even if $\mathrm{PCa}$ is seen in TURP chips. So, after PSA era, IPCa can be diagnosed at lower PSA levels. Lee et $\mathrm{al}^{21}$ in their cohort study showed that 91 patients had PSA $<4.0 \mathrm{ng} / \mathrm{mL}$ before TURP, and the remaining 65 patients had PSA $>4.0 \mathrm{ng} / \mathrm{mL}$, and of their 65 patients, 12 underwent core prostate biopsy and were found to have peripheral $\mathrm{PCa}$ on biopsy. In other words, these patients were more likely to be diagnosed as cancer-free by prostate biopsy if they did not undergo TURP. ${ }^{21}$ Yang et $\mathrm{al}^{13}$ in their study evaluated 340 cystoprostatectomy samples of patients who had undergone radical cystoprostatectomy for the treatment of bladder cancer in the People's Republic of China. They showed that $180(53 \%)$ patients had either IPCa or urothelial cancer in the prostate. Of them, 28\% (95 patients) had PCa and 34\% (115 patients) had urothelial carcinoma of the prostate. The incidence of IPCa was $21 \%$ and $31 \%$, respectively, during the two periods of their study (2004-2008 and 2009-2014). Despite this high prevalence on histological examinations, few prostate cancers may not detected by screening, and even in intensely screened populations most are left undiscovered. Therefore, a key research implication is to find better methods sooner for distinguishing progressive from indolent PCas. ${ }^{24}$ Kitamura et $\mathrm{al}^{25}$ reported that TURP should be performed only in patients complaining of LUTS. This was related to 
major clinically nonsignificant PCa diagnosed by performing concomitant sextant biopsy and transition zone biopsy. However, van Renterghem et $\mathrm{al}^{26}$ reported improvement of bladder outlet obstruction, normalization of PSA, and diagnosis of clinically significant PCa by performing TURP. Kim et $\mathrm{al}^{27}$ evaluated 165 patients who underwent TURP. They compared the detection rate of $\mathrm{PCa}$ between patients who had TRUS-Bx before TURP (group A) and those who did not (group B). Their results showed no significant difference between groups A and B. They suggested that BPH patients in whom PCa is suspected and who have LUTS with a previously negative TRUS-Bx result should undergo TURP, which results in immediate improvement in bladder outlet obstruction and early diagnosis of clinically significant transition zone PCa. Zigeuner et $\mathrm{al}^{14}$ showed that in their study of detection of PCa by TURP or open surgery in patients with previously negative TRUS-Bx, the overall probability of diagnosing PCa by TURP in patients with obstructive voiding symptoms and clinical suspicion for $\mathrm{PCa}$, but negative prostate biopsy, was less than $8 \%$, and so they did not recommend TURP for diagnostic purposes.

\section{Conclusion}

We showed that PCa had higher incidence in the OP group rather than in the TURP group. However, it cannot be concluded that OP's ability for detecting PCa is higher than TURP, and so more studies are needed. PSA levels have high sensitivity, but it are not specific enough to determine PCa. The cut-off point of PSA for detecting PCa in our study was $3.8 \mathrm{ng} / \mathrm{mL}$, which is similar to that used in other studies. PSA levels and familial history of PCa were two predictors used in our study to determine $\mathrm{PCa}$. In addition to PSA screening, a positive result on DRE is recommended for detecting PCa.

We had several limitations in this study. Our investigation was a retrospective study that included many different surgical treatment modalities, potentially modifying the amount of tissue that was submitted for review. We did not access data regarding cancer grading (TNM system) of all patients for more evaluation.

We recommend further prospective studies with multicentric populations be carried out to evaluate this comparison including the TNM system and other related variables.

\section{Acknowledgments}

We thank the hospital medical records staff who helped us with data collection. The authors thank Saeed Montazeri for his cooperation in editing this paper.

\section{Disclosure}

The authors report no conflicts of interest in this work.

\section{References}

1. Khattak W. Incidence of prostate cancer following trans-urethral resection of prostate (TURP) for clinically benign symptomatic enlarged prostate with normal prostatic specific antigen (PSA). Ophthalmology. 2014;12(2):151.

2. Cal C, Uslu R, Gunaydin G, Ozyurt C, Omay SB. Doxazosin: a new cytotoxic agent for prostate cancer? BJU Int. 2000;85(6):672-675.

3. Kehinde EO, Mojiminiyi OA, Sheikh M, et al. Age specific reference levels of serum prostate specific antigen and prostate volume in healthy Arab men. BJU Int. 2005;96(3):308-312.

4. Karim $H$, Hooda $M$, Islam $M$, et al. Incidence of chips positive carcinoma of prostate following TURP for clinically benign prostatic hyperplasia patients with normal serum PSA. Bangladesh JUrol. 2011;14(1):14-18.

5. Kurahashi N, Sasazuki S, Iwasaki M, Inoue M, Tsugane S; JPHC Study Group. Green tea consumption and prostate cancer risk in Japanese men: a prospective study. Am J Epidemiol. 2008;167(1):71-77.

6. Mariotto AB, Etzioni R, Krapcho M, Feuer EJ. Reconstructing PSA testing patterns between black and white men in the US from Medicare claims and the National Health Interview Survey. Cancer. 2007;109(9):1877-1886.

7. Stattin P, Carlsson S, Holmström B, et al. Prostate cancer mortality in areas with high and low prostate cancer incidence. J Natl Cancer Inst. 2014;106(3):dju007.

8. D'Ambrosio GG, Campo S, Cancian M, Pecchioli S, Mazzaglia G. Opportunistic prostate-specific antigen screening in Italy: 6 years of monitoring from the Italian general practice database. Eur J Cancer Prev. 2010;19(6):413-416.

9. Napal Lecumberri S, Lameiro Couso FJ, Rubio Navarro C, Gómez Dorronsoro M, Larrínaga Liñero B, Ipiéns Aznar A. Estudio de la progresión del cáncer de próstata incidental según el tipo de tratamiento aplicado [A study of the progression of the incidental prostate cancer depending on the kind of treatment performed]. Actas Urol Esp. 2007;31(8):810-818. Spanish.

10. Herranz-Amo F, Diez-Cordero JM, Verdu-Tartajo F, Bueno-Chomon G, Leal-Hernandez F, Bielsa-Carrillo A. Need for intravenous urography in patients with primary transitional carcinoma of the bladder? Eur Urol. 1999;36(3):221-224.

11. Fernández RE, Gómez VF, Alvarez CL, Ruibal MM, Chantada AV, González MM. Estudio clínico-patológico sobre el cáncer de próstata incidental en pacientes intervenidos bajo el supuesto diagnóstico de HBP sintomática [Clinicopathological study of incidental cancer prostate in patients undergoing surgery for symptomatic diagnosis of BPH]. Actas Urol Esp. 2006;30(1):33-37. Spanish.

12. Mai KT, Isotalo PA, Green J, Perkins DG, Morash C, Collins JP. Incidental prostatic adenocarcinomas and putative premalignant lesions in TURP specimens collected before and after the introduction of prostrate-specific antigen screening. Arch Pathol Lab Med. 2000;124(10):1454-1456.

13. Yang X, Monn MF, Liu L, et al. Incidental prostate cancer in Asian men: high prevalence of incidental prostatic adenocarcinoma in Chinese patients undergoing radical cystoprostatectomy for treatment of bladder cancer and selection of candidates for prostate sparing cystectomy. Prostate. 2015;75(8):845-854.

14. Zigeuner R, Schips L, Lipsky K, et al. Detection of prostate cancer by TURP or open surgery in patients with previously negative transrectal prostate biopsies. Urology. 2003;62(5):883-887.

15. Tombal B, De Visccher L, Cosyns JP, et al. Assessing the risk of unsuspected prostate cancer in patients with benign prostatic hypertrophy: a 13-year retrospective study of the incidence and natural history of T1a-T1b prostate cancers. BJU Int. 1999;84(9):1015-1020.

16. Voigt S, Hüttig F, Koch R, et al. Risk factors for incidental prostate cancer who should not undergo vaporization of the prostate for benign prostate hyperplasia? Prostate. 2011;71(12):1325-1331.

17. Jones JS, Follis HW, Johnson JR. Probability of finding T1a and T1b (incidental) prostate cancer during TURP has decreased in the PSA era. Prostate Cancer Prostatic Dis. 2009;12(1):57-60. 
18. Helfand BT, Anderson CB, Fought A, Kim DY, Vyas A, McVary KT. Postoperative PSA and PSA velocity identify presence of prostate cancer after various surgical interventions for benign prostatic hyperplasia. Urology. 2009;74(1):177-183.

19. Yoo C, Oh CY, Kim SJ, et al. Preoperative clinical factors for diagnosis of incidental prostate cancer in the era of tissue-ablative surgery for benign prostatic hyperplasia: a Korean multi-center review. Korean $J$ Urol. 2012;53(6):391-395.

20. Lee LS, Thiruneelakandasivam S, Hong MK, et al. Are transrectal prostate biopsies routinely indicated in patients with incidentally diagnosed prostate cancer following transurethral resection of the prostate for benign disease? Urol Int. 2013;91(4):397-403.

21. Lee DH, Chung DY, Lee KS, et al. Clinical experiences of incidental prostate cancer after transurethral resection of prostate (TURP) according to initial treatment: a study of a Korean high volume center. Yonsei Med J. 2014;55(1):78-83.

22. Trpkov K, Thompson J, Kulaga A, Yilmaz A. How much tissue sampling is required when unsuspected minimal prostate carcinoma is identified on transurethral resection? Arch Pathol Lab Med. 2008;132(8):1313-1316.
23. Otto B, Barbieri C, Lee R, et al. Incidental prostate cancer in transurethral resection of the prostate specimens in the modern era. Adv Urol. 2014;2014:627290.

24. Bell KJ, Del Mar C, Wright G, Dickinson J, Glasziou P. Prevalence of incidental prostate cancer: a systematic review of autopsy studies. Int J Cancer. 2015;137(7):1749-1757.

25. Kitamura H, Masumori N, Tanuma Y, et al. Does transurethral resection of the prostate facilitate detection of clinically significant prostate cancer that is missed with systematic sextant and transition zone biopsies? Int J Urol. 2002;9(2):95-99.

26. van Renterghem K, Van Koeveringe G, Achten R, van Kerrebroeck P. A new algorithm in patients with elevated and/or rising prostatespecific antigen level, minor lower urinary tract symptoms, and negative multisite prostate biopsies. Int Urol Nephrol. 2010;42(1): 29-38.

27. Kim DK, Kim SJ, Moon HS, et al. The role of TURP in the detection of prostate cancer in $\mathrm{BPH}$ patients with previously negative prostate biopsy. Korean J Urol. 2010;51(5):313-317.
Research and Reports in Urology

\section{Publish your work in this journal}

Research and Reports in Urology is an international, peer-reviewed, open access journal publishing original research, reports, editorials, reviews and commentaries on all aspects of adult and pediatric urology in the clinic and laboratory including the following topics: Pathology, pathophysiology of urological disease; Investigation and treatment of

\section{Dovepress}

urological disease; Pharmacology of drugs used for the treatment of urological disease. The manuscript management system is completely online and includes a very quick and fair peer-review system, which is all easy to use. Visit http://www.dovepress.com/testimonials.php to read real quotes from published authors. 